\title{
CORA: Aplikasi Baca Untuk Lansia Berbasis Android Menggunakan Teknologi Optical Characteristic Recognition (OCR)
}

\author{
M. Arinal Haqil Ghifari, Andi Susilo \\ Universitas Respati Indonesia \\ Email: qioghif@gmail.com, as@fti.urindo.ac.id
}

\begin{abstract}
Abstrak
Seiring proses penuaan yang dialami para lansia, maka lansia akan mengalami penurunan fungsi melihat. Hal ini menyebabkan menurunnya kemampuan membaca lansia dan mengganggu aktifitas membaca para lansia. Solusinya adalah menghasilkan suatu produk aplikasi berbasis Android yang dapat membantu para lansia dalam aktifitas membaca dengan menggunakan teknologi OCR. Penelitian ini menggunakan metodologi System Development Life Cycle jenis Rapid Application Development model Prototyping sebagai skema siklus pengembangan sistem dan menggunakan Unified Modelling Language sebagai rancangan pemodelan. Aplikasi dibangun menggunakan bahasa pemrograman Java, database SQLite, library Optical Character Recognition (OCR) dan Text-To-Speech dan Android Studio sebagai editor pemrograman Java Android, Hasil akhir berupa aplikasi bantu baca untuk lansia dengan menggunakan teknologi OCR, dimana aplikasi ini memiliki fitur pindai gambar pada teks dokumen cetak untuk dikonversi ke teks digital, kemudian hasil teks digital dikonversi menjadi audio dengan menggunakan text-to-speech. Pengguna cukup mendengarkan aplikasi membaca teks hasil pindai memalui smartphone Android.
\end{abstract}

Kata kunci: Android, lansia, Optical Character Recognition (OCR), Text-To-Speech.

\section{CORA: ANDROID-BASED READING APPLICATION FOR ELDERLY USING OPTICAL CHARACTER RECOGNITION (OCR) TECHNOLOGY}

\begin{abstract}
Along with the aging process of elderly, eyes function will decrease. This will also decrease their reading ability and disrupt their reading activities. On the other hand, this problem has not been matched by an application that can help solve their reading activities problem. The purpose of this study is to produce an Android-based application product that can help the elderly in reading activities using OCR technology. This research uses the System Development Life Cycle Rapid Application Development Prototyping methodology as a system development cycle scheme and uses the Unified Modeling Language as a modeling design. The application is built by using the Java programming language, SQLite database, Optical Character Recognition (OCR) library, Text-To-Speech, and Android Studio as java android programming editors. The end result is a reading aid application for the elderly using OCR technology, where the application has features to scan images on printed document text to convert to digital text, then the results of digital text are converted into audio using text-tospeech. So that after going through the process, users simply listen to the application to read the scanned text through an Android smartphone.
\end{abstract}

Keywords: Android, Elderly, Optical Character Recognition (OCR), Text-To-Speech.

\section{PENDAHULUAN}

Pertumbuhan penduduk Indonesia berdasarkan data Statistik Penduduk Lanjut Usia (BPS, 2016) menunjukkan bahwa jumlah Lansia Indonesia mencapai sebanyak 22,48 juta jiwa atau $8,69 \%$ dari total penduduk Indonesia. Mengacu pada proyeksi penduduk tahun 2005-2025, dijelaskan bahwa penduduk lansia akan mengalami pertumbuhan secara signifikan yakni sebesar $12.65 \%$.

Peningkatan angka harapan hidup dan bertambah jumlah lansia di satu sisi merupakan salah satu keberhasilan dalam pembangunan sosial dan ekonomi, namun keberhasilan tersebut mempunyai konsekuensi dan tanggung jawab untuk memberikan perhatian lebih serius, karena dengan bertambahnya usia, kondisi dan kemampuan lansia untuk beraktivitas semakin menurun. Proses penuaan dapat menyebabkan beberapa permasalahan. Seperti penurunan fungsi indra pada lansia, salah satunya ialah menurunnya fungsi penglihatan. World Health Organization (WHO, 2013) menjelaskan sedikitnya terdapat 135 juta orang yang mengalami disabilitas penglihatan yang sangat signifikan. Hal ini tentunya akan mengganggu aktifitas para lansia, khususnya dalam kegiatan membaca. 
Didorong oleh kondisi tersebut, menjadi motivasi tersendiri untuk membuat aplikasi yang membantu lansia dengan penurunan fungsi penglihatan.

Pada aplikasi ini, pengguna memanfaatkan kamera smartphone untuk proses input kata dengan memanfaatkan teknologi OCR, sehingga pengguna cukup mengambil gambar kata yang akan dibaca tanpa harus mengetik manual pada area teks input. Kemudian teks yang dientri tersebut, diproses menjadi audio dengan menggunakan teknologi Textto-Speech.

\section{METODE}

Penelitian ini dilaksanakan pada lingkungan Pendidikan Kesejahteraan Keluarga (PKK) yang bertempat di RT 03 RW 01, Cipayung, Bambu Apus, Jakarta Timur pada 10 Responden. Dengan waktu pengumpulan data dimulai dari 29 April 2018 sampai 23 Agustus 2018.

Pendekatan penelitian pembuatan aplikasi ini menggunakan System Development Life Cycle (SDLC) dengan metodologi Rapid Application Development (RAD) model prototyping yaitu siklus diulang secara terus menerus sampai prototype berhasil memenuhi syarat tahapan yang dilalui seperti terlihat pada Gambar 1:

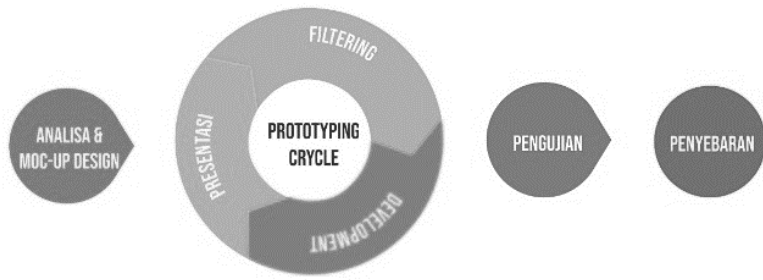

Gambar 1. Model prototyping aplikasi bantu baca lansia

Tahapan - tahapan yang dilakukan dalam pembuatan aplikasi CORA yaitu :

a. Perencanaan

Dalam fase perencanaan tahapan - tahapan yang akan dilakukan adalah penentuan kebutuhan dan studi kelayakan,:

b. Analisis

Pada tahap analisis akan di jelaskan identifikasi kebutuhan, dua pemodelan yaitu Functional modeling dan Behavioral modeling.

c. Perancangan

Pada tahap perancangan ini meliputi identifikasi spesifikasi aplikasi dan alat yang dibutuhkan dalam pengembangan, perancangan antarmuka, serta logik user interface.

d. Implementasi

Pada tahapan implementasi dilakukan pembuatan aplikasi secara keseluruhan yang meliputi pembuatan aplikasi sesuai dengan tahapan analisis dan perancangan, kemudian dilanjutkan pada fase implementasi dan melakukan proses uji coba aplikasi pada smartphone Android.

\section{e. Pengujian}

Pada fase ini aplikasi akan diuji pada kondisi sebenarnya, yaitu kepada kondisi aktifitas membaca para lansia di lingkungan RT 03 Cipayung, Bambu Apus. Simulasi awal mengajak lansia untuk mencoba aplikasi, dengan mengambil gambar teks uji coba yang telah disiapkan untuk di pindai oleh aplikasi, dan dilanjut dengan mendengarkan hasil pindai teks serta setelah menggunakan aplikasi tersebut, pengguna akan diwawancarai untuk memberi testimoni terkait fitur aplikasi, apakah membantu atau tidak dalam implementasinya.

\section{HASIL}

a. Spesifikasi Software dan Hardware

Perangkat lunak (software) dan perangkat keras (hardware) yang digunakan dalam perancangan dan implementasi aplikasi CORA ini menggunakan beberapa perangkat keras yang dijelaskan pada Tabel Tabel 1. Spesifikasi Software dan Hardware

\begin{tabular}{lll}
\hline No. & Nama Perangkat & \multicolumn{1}{c}{ Spesifikasi } \\
\hline 1. & Laptop & Intel Celeron-N2840 \\
& & RAM 4 GB DDR3 \\
& & Hardisk 500GB \\
& & OS windows 10 V-1803 \\
& & \\
\hline 2. & Smartphone & processor Quad-core 1.5 \\
& & GHz Cortex-A53 \\
& & RAM 2 GB \\
& & memory internal 16 GB \\
& & OS Android Lollipop \\
\hline 3. & IDE Android Studio & Versi Android Studio 3.1 \\
\hline & & \\
\hline
\end{tabular}

\section{b. Tampilan Fisik Antarmuka}

Adapun tampilan user interface setelah aplikasi CORA selesai dibuat, dijelaskan secara rinci sebagai berikut:

1) Tampilan halaman utama

Pada halaman utama terdapat dua kondisi, yaitu kondisi tampilan halaman utama tanpa sebuah berkas dan halaman utama dengan sebuah berkas. Pada kondisi halaman utama tanpa berkas, hanya menampilkan tombol tambah berkas yang berfungsi untuk menambahkan berkas, sedangkan dengan kondisi tampilan yang telah memiliki berkas, terdapat list view yang memiliki tombol fungsi berupa icon tombol edit dan memutar suara berkas, serta ketika menekan lama salah satu berkas, akan muncul ikon ganti nama dan hapus berkas. Adapun secara keseluruhan, pada tampilan ini terdapat tombol menu yang berisi pengaturan, tentang dan bantuan. Selain itu, juga terdapat tombol menambahkan berkas (Gambar 2). 


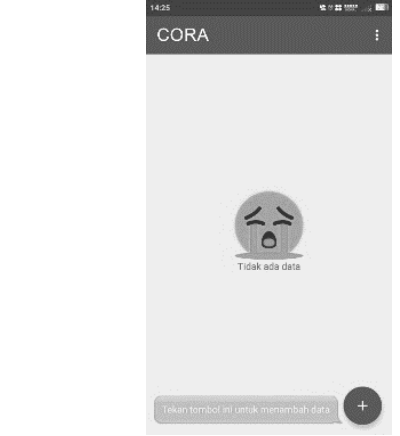

Gambar 2. Tampilan tampilan halaman utama

2) Perancangan Halaman Tambah berkas dan Editor

Pada halaman ini, akan terdapat tombol ikon kamera dan tombol ikon gambar. Ikon kamera menandakan pengguna bisa menambahkan berkas langsung dengan memotret gambar dan dengan tombol ikon gambar, pengguna bisa langsung mencari berkas di file manager.

Setelah proses pemindaian teks dengan OCR selesai. Berkas hasil pindai akan dimasukkan pada pengedit teks. Kita bisa mengedit teks, memutar suara teks, menghapus dan menyimpan, serta terdapat tombol pilih dialek bahasa untuk menyesuaikan bahasa teks yang dibaca (Gambar 3).

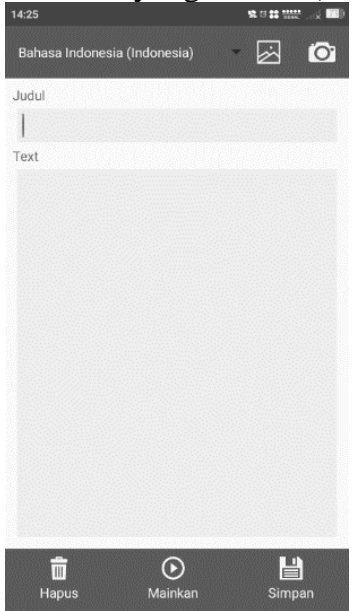

Gambar 3. Halaman tambah berkas dan editor

3) Tampilan Halaman Menu

Pada halaman utama, terdapat tombol menu. Ketika ditekan, akan muncul halaman dari sisi kiri layar (Gambar 4).

\begin{tabular}{|c|c|}
\hline 20:48 & 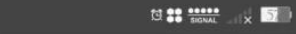 \\
\hline Menu Utama & Pengaturan \\
\hline \multirow{4}{*}{$\begin{array}{l}\text { File Cora } \\
\text { 21-8-2018,19:22:21 } \\
\text { Sebab terlalu banyak ya } \\
\text { mengutarakan kebencia } \\
\text { ingin lebih banyak berbi } \\
\text { cinta denganmu. } \\
\ldots\end{array}$} & Bantuan \\
\hline & Tentang \\
\hline & Keluar \\
\hline & \\
\hline
\end{tabular}

Gambar 4 Tampilan halaman menu

4) Tampilan Halaman Pengaturan

Halaman pengaturaan akan menampilan tombol untuk mengatur dialek bahasa pembaca, pengaturan pemilihan bahasa tersebut dimaksudkan untuk mengatur bahasa default yang dipakai aplikasi (Gambar 5).

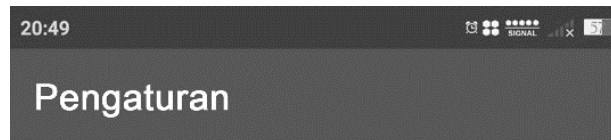

Pilih Bahasa Suara

Bahasa Indonesia (Indonesia)

Gambar 5. Tampilan halaman pengaturan

5) Tampilan Halaman Bantuan

Halaman bantuan berisi teks deskripsi singkat dalam menggunakan aplikasi (Gambar 6)

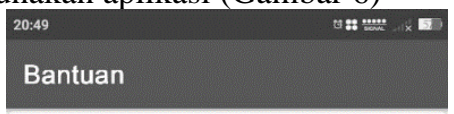

SELAMAT DATANG DI APLIKASI CORA.

Silahkan klik tombol + untuk menambahkan file. Dan pilih salah satu cara input file, dengan icon dan [0] Ambil gambar yang anda inginkan, dan tunggu proses OCR mengkonversi gambar ke teks. Hasil konversi akan muncul di editor. Silahkan klik tombol $\circ$ untuk memutar tombol 블 untuk mengyimpan, pastikan nama file telah di isi. tombol to untuk hapus file.

Untuk mengubah dialek bahasa default, silahkan klik menu > Pengaturan >Pilih bahasa.

Jika anda mengalami kesulitan tentang penggunaan aplikasi ini, silahkan hubung +62 81808480822 atau email ke qioghif@gmail.com.

Gambar 5. Tampilan halaman bantuan

6) Tampilan Halaman Tentang

Halaman tentang berisi terkait deskripsi singkat tentang aplikasi (Gambar 7). 


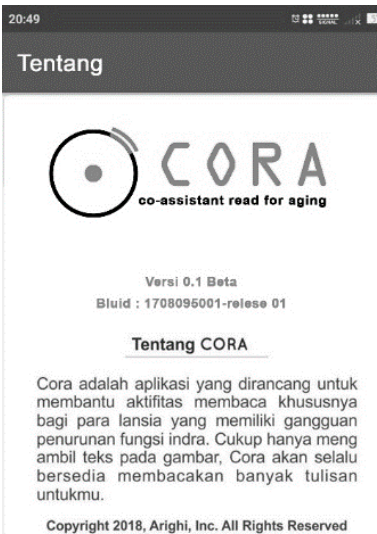

Gambar 7. Tampilan halaman tentang CORA
UAT dilakukan untuk menguji penerimaan user terhadap aplikasi yang dibuat pengujian ini bertujuan untuk menganalisis kegunaan dari aplikasi yang telah dibuat bagi user.

Analisis ini dilakukan dengan melakukan pengujian secara objektif pada 10 responden untuk menggunakan aplikasi CORA. Aplikasi dipasangkan pada spesifikasi dan merk smartphone yang beragam milik pengguna. Setelah itu, disiapkan dua jenis teks uji. Teks uji pertama digambarkan dengan sebuah artikel dengan font Arial ukuran 12 dan dengan jenis besar kecil font yang bervariasi.

Setelah kuesioner pertama selesai diisi, berlanjut pada pengisian kuesiner kedua untuk pengujian (UAT), kuesioner tersebut dimaksudkan untuk mengetahui kegunaan aplikasi dan persentase yang diperoleh dari beberapa tanggapan pernyataan yang diajukan pada responden pengguna aplikasi (Tabel 2).

Tabel 2. Hasil Pengujian pada responden (UAT)

\begin{tabular}{lccccc}
\hline \multicolumn{1}{c}{ Pernyataan } & $\begin{array}{c}\text { San } \\
\text { gat } \\
\text { Set } \\
\text { uju }\end{array}$ & $\begin{array}{c}\text { Set } \\
\text { uju }\end{array}$ & $\begin{array}{c}\text { Kuran } \\
\text { g } \\
\text { Setuju }\end{array}$ & $\begin{array}{c}\text { Tidak } \\
\text { Setuju }\end{array}$ & $\begin{array}{c}\text { Respo } \\
\text { nden }\end{array}$ \\
\hline $\begin{array}{l}\text { Fitur dan menu berfungsi } \\
\text { dengan baik }\end{array}$ & 5 & 3 & 1 & 1 & 10 \\
\hline $\begin{array}{l}\text { Desain antarmuka aplikasi } \\
\text { cukup sederhana dan } \\
\text { memudahkan saya dalam } \\
\text { menggunakan aplikasi. }\end{array}$ & 3 & 6 & 1 & 0 & 10 \\
\hline $\begin{array}{l}\text { Aplikasi mempermudah saya } \\
\text { untuk memahami isi bacaan }\end{array}$ & 3 & 5 & 1 & 1 & 10 \\
\hline $\begin{array}{l}\text { Aplikasi bisa menjadi } \\
\text { alternatif yang dipilih dalam } \\
\text { membantu aktifitas membaca }\end{array}$ & 5 & 4 & 0 & 1 & 10 \\
\hline $\begin{array}{l}\text { Penilaian aplikasi Cora secara } \\
\text { keseluruhan }\end{array}$ & 2 & 6 & 1 & 1 & 10 \\
\hline Hasil total & 18 & 24 & 4 & 4 & \\
\hline Hasil Presentase & 36 & 48 & $8 \%$ & $8 \%$ & $100 \%$ \\
\hline
\end{tabular}

Berdasarkan Tabel 2 diperoleh dari hasil penilaian 10 responden, setiap responden menanggapi 5 pernyataan, sehingga terdapat sebanyak 50 pernyataan. Total hasil respon dengan rincian $18(36 \%)$ sangat setuju, $24(48 \%)$ setuju, 4 (8\%) kurang setuju, 4 (8\%) tidak setuju.

\section{SIMPULAN}

Berdasarkan hasil studi, penelitian, analisis, perancangan, implementasi, dan uji coba yang telah dilakukan dapat disimpulan bahwa aplikasi ini berjalan dengan baik pada Android dengan versi OS minimal v4.0 (Jelly Bean), serta mendukung Android versi terbaru yaitu v8.0 (Oreo). Hasil pengujian User Acceptance Test (UAT) menunjukkan respon terhadap kinerja dan pemanfaatan aplikasi relatif dominan respon positif. Sehingga, aplikasi CORA dapat dijadikan sebagai alat bantu baca bagi lansia yang memiliki penurunan fungsi indra penglihatan.

\section{DAFTAR PUSTAKA}

1. Dennis, Wixom, and Tegarden. (2015). System Analysis \& Design: An ObjectOriented Approach with UML. Fifth Edition, Wiley Publisher.

2. Rao, Sastry, Chakravarthy, and Kalyanchakravarthi. (2016). “Optical Character Recognition Technique Algorithms". Journal of Theoretical and Applied Information Technology vol. 83, no. 1. ISSN: 1992-8645.

3. Samsudin and Putra. (2014). "Perancangan Aplikasi Text to Speech Pengenalan Kalimat Dalam Bahasa Inggris Menggunakan Metode Linear Predictive Coding". KeTIK: 61. ISBN: 979-458-766-4

4. Mohammad, F., Anarase, J., Shingote, M., \& Ghanwat, P. (2014). “Optical Character Recognition Implementation Using Pattern Matching". International Journal of Computer Science and Information Technologies, 2088-2090.

5. Lestari. 2012. Hubungan Intensitas Kebiasaan membaca Al-Quran dengan Fungsi Kognitif Lanjut Usia di Wilayah Kerja Puskesmas Kecamatan Ciseeng Kabupaten Bogor 2012 [SKRIPSI]. Jakarta Selatan [ID]: UIN Syarif Hidayatullah. 
6. Badan Pusat Statistik (BPS). (2006). Statistik Penduduk Lanjut Usia. Jakarta.

7. Sandhika, Hakim, and Lukman. (2014). "Penerapan Teknik OCR (Optical Character Recognition) Pada Aplikasi Terjemahan Kitab Fiqih Safinah An-Naja Menggunakan Readiris". Seminar Nasional Informatika 2014 (semnasIF 2014). ISSN: 1979-2328.

8. Kristina, Wahyu. (2016). “Implementasi Optical Character Recognition Berbasis Backpropagation untuk Text to Speech Perangkat Android". IJEIS vol 6. ISSN: 20883714.
9. Chauduri, Mandaviya, Badelia, Ghosh (2017) "Optical Character Recognition Systems for Different Languages with Soft Computing". Book Series: Studies in Fuzziness and Soft Computing. Springer Publisher. ISBN: 978-3-319-50252-6 